\title{
A dynamic compartment model for evaluating the transfer of radionuclide into rice-plants after an acute release
}

\author{
D.K. Keum, H.S. Lee, H.J . Choi, H.S. Kang and C.W. Lee \\ Nuclear Environment Research Department, Korea Atomic Energy Research Institute \\ 150 Deokjindong, Yuseong, Daejeon 305-323, Korea
}

\begin{abstract}
A dynamic compartment model was developed to evaluate the transport of accidentally released radionuclides onto rice-fields. In the model, the surface water compartment and shoot-base absorption were introduced to account for the effect of an irrigation which is essential to rice cultivation. Allowance was made for the effect of a soil mixing by a plough and an irrigation before transplanting the rice. The rate of root-uptake and shoot-base absorption were modeled in terms of the function of the biomass. In order to test the validation of the model, some ${ }^{137} \mathrm{Cs}$ deposition experiments were carried out for several years while cultivating rice in a greenhouse using soils sampled from rice-fields around Kori, Yonggwang and Ulchin nuclear power plants in Korea. The model prediction agreed well to the experimental results within one order of magnitude.
\end{abstract}

\section{INTRODUCTION}

Most dynamic models for the assessment of the radionuclide transport in the food-chain and human ingestion dose resulting from a nuclear accident have focused on the agricultural system of dry farming fields, and usually divide a soil system into three compartments, i.e., surface soil, root-zone soil, and deep soil, to account for the transfer of the radionuclide within the soil [1-4]. However, in the cultivation of rice-plants there is always the flooding water on the rice-fields during the growth stage by the supply of irrigation water. In some transport experiments of radionuclide with rice-plants, the flooded rice absorbed more cesium from the contaminated water than from the soil $[5,6]$. The enhancement of the absorption occurs as a result of the shoot-base absorption, a generic term representing the absorption from the stem bases and surface roots before being fixed by the soil. It is therefore necessary for a transport model to consider the shoot-base absorption in addition to the root-uptake. This study aims at presenting a dynamic compartment model, which is especially appropriate for predicting the transfer of radionuclide deposited onto a flooded rice-plant after an accidental release.

\section{MODEL}

The present model consists of six independent compartments, i.e., rice-body, grain, surface-water, root-zone-soil, fixed-soil and deep-soil. It takes into account the transfer processes, including radioactive decay, percolation, leaching, shoot-base absorption, root-uptake, weathering, translocation, fixation to the soil by adsorption and desorption, and soil-mixing by ploughing (Figure 1). The structure of the model and transfer processes considered are similar to the existing dynamic compartment models [1-4], but it has two characteristics, which are distinct from the existing models. One is the surface water compartment to conceptualize the flooding water by an irrigation during the growth season which is normal in rice cultivation. The other is the shoot-base absorption that represents the 
direct transfer of the radionuclide from the flooding surface water to the rice-plant. The redistribution of the radionuclide between the surface water and soil compartment resulting from a soil mixing by a plough and an irrigation before transplanting is also taken into account.

The rate of the root-uptake and shoot-base absorption depending on the growth stage of the biomass is modeled in terms of the growth equation of the biomass of a sigmoid type. With the assumption of the linear transfer rates of the radionuclide between the compartments, the resulting model equations consist of a set of ordinary differential equations and are solved by the fourth order Runge-Kutta algorithm. Details of the model are given elsewhere [7].

\section{EXPERIMENT}

Soils for the rice cultivation were all sampled from rice-fields within $5 \mathrm{~km}$ of the Kori, Yonggwang and Ulchin nuclear power plants in Korea. Rice was cultivated in culture boxes placed in a greenhouse. Major farming dates and the radionuclide treatment methods are summarized in Table 1. For the experiments with the Kori soil, a solution of ${ }^{137} \mathrm{Cs}$ was independently applied at three different times (May 2,

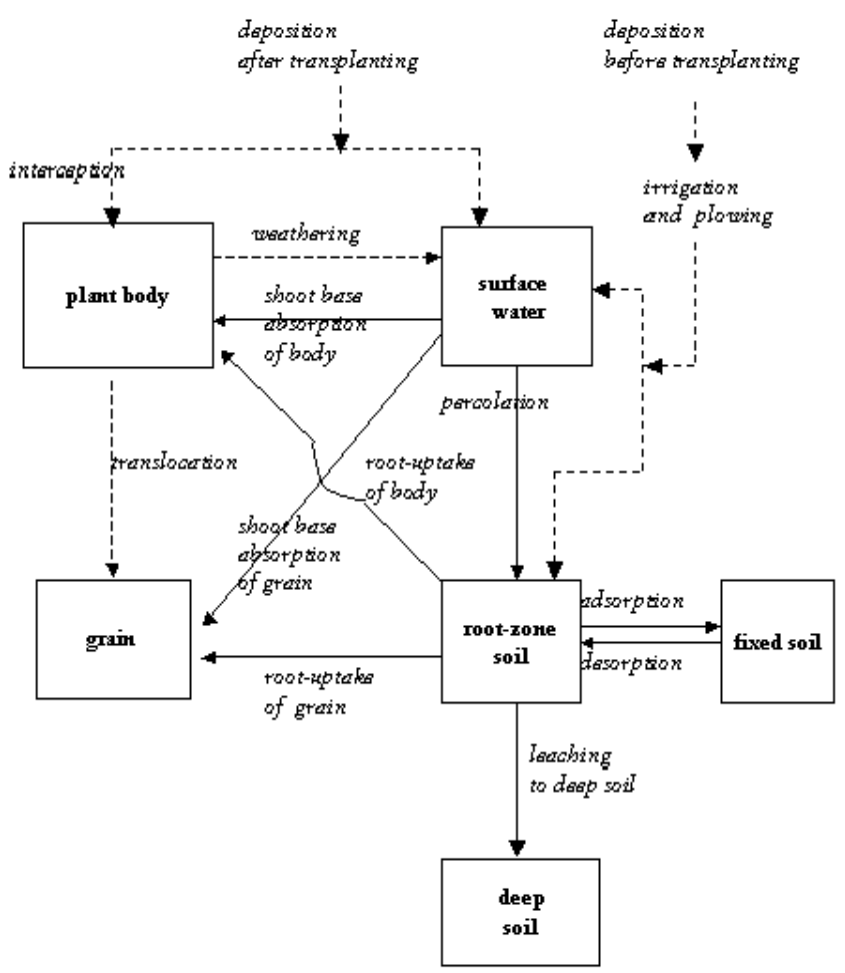

Figure 1. Conceptual diagram of food chain model used in the present study June 1 and August 12, 1998). The first application was to simulate the deposition before transplanting and the other two were to simulate the deposition during the growth. For the deposition before transplanting, a mixed solution of ${ }^{137} \mathrm{Cs}$ was directly applied to the dried soil surface. Subsequently, the contaminated soil was uniformly mixed up to a depth of about $0.15 \mathrm{~m}$ using a trowel, and ploughed once more with an irrigation at 10 days before transplanting.

Table 1. Transplanting, ear-emergence, harvest and deposition dates for each experiment.

\begin{tabular}{|l|l|l|l|l|l|l|}
\hline Soil used & $\begin{array}{l}\text { Transplanting } \\
\text { date }\end{array}$ & $\begin{array}{l}\text { Ear- } \\
\text { emergence } \\
\text { date }\end{array}$ & Harvest date & Deposition date & $\begin{array}{l}\text { Radionuclide } \\
\text { treatment method }\end{array}$ & $\begin{array}{l}\text { Farming } \\
\text { period }\end{array}$ \\
\hline Kori & May 21, 1998 & August 16 & October 12 & $\begin{array}{l}\text { May 2, 1998 } \\
\text { June 1, 1998 } \\
\text { August 12, 1998 }\end{array}$ & $\begin{array}{l}\text { Soil treatment } \\
\text { Surface water treatment } \\
\text { Surface water treatment }\end{array}$ & 1 year \\
\hline $\begin{array}{l}\text { Yong- } \\
\text { gwang }\end{array}$ & $\begin{array}{l}\text { May 22, 1999 } \\
\text { May 25, 2000 } \\
\text { May 22, 2001 } \\
\text { May 22, 2002 }\end{array}$ & August 13 & $\begin{array}{l}\text { October 12 } \\
\text { October 11 } \\
\text { October 15 } \\
\text { October 15 }\end{array}$ & May 4, 1999 & Soil treatment & 5 years \\
\hline Ulchin & $\begin{array}{l}\text { May 22, 2001 } \\
\text { May 22, 2002 } \\
\text { May 22, 2002 }\end{array}$ & August 13 & $\begin{array}{l}\text { October 15 } \\
\text { October 15 } \\
\text { October 15 }\end{array}$ & May 10, 2001 & Soil treatment & 3 years \\
\hline
\end{tabular}


For the deposition during the growth, a mixed solution of ${ }^{137} \mathrm{Cs}$ was evenly applied to the surface of the irrigation water without contaminating the plant surface using a micropipette. For the experiments with the Yonggwang and Ulchin soils, the radionuclide was added to the soil before transplanting for the first year, and rice was cultivated consecutively for several years in the contaminated soil without the additional treatment of the radionuclide.

The surface flooding water maintained the water level of about 2-5 cm (average $3 \mathrm{~cm}$ ) during the period of irrigation. Irrigation water was supplied from ten days before transplanting to mid-September, so no surface water was observed around the end of September. The harvested rice was dried after separating it to the straw and ears, and the activity of each part was measured by a $\gamma$-spectrometer equipped with HPGe. The counting time ranged from 0.5 to 2 hours depending on the samples and the detection error was within $10 \%$. Details of the experiment are elsewhere $[8,9]$.

\section{RESULTS AND DISCUSSION}

\subsection{Compartment activities}

Figure 2 shows the time-dependent activity of the surface water, root-zone soil, rice-body, and grain body compartments for the experiments with the Kori soil. In the figure the abbreviations, DP, IP, TP, $\mathrm{EE}, \mathrm{NSW}$, and HV stand for the deposition, irrigation and ploughing (May 11), transplanting (May 21), ear-emergence (August 16), no-surface-water (September 30), and harvest (October 12), respectively.

The activity of the surface water for the deposition before transplanting (DP1, May 2), increases sharply at 10 days before transplanting as a result of the irrigation and ploughing (IP, May 11).
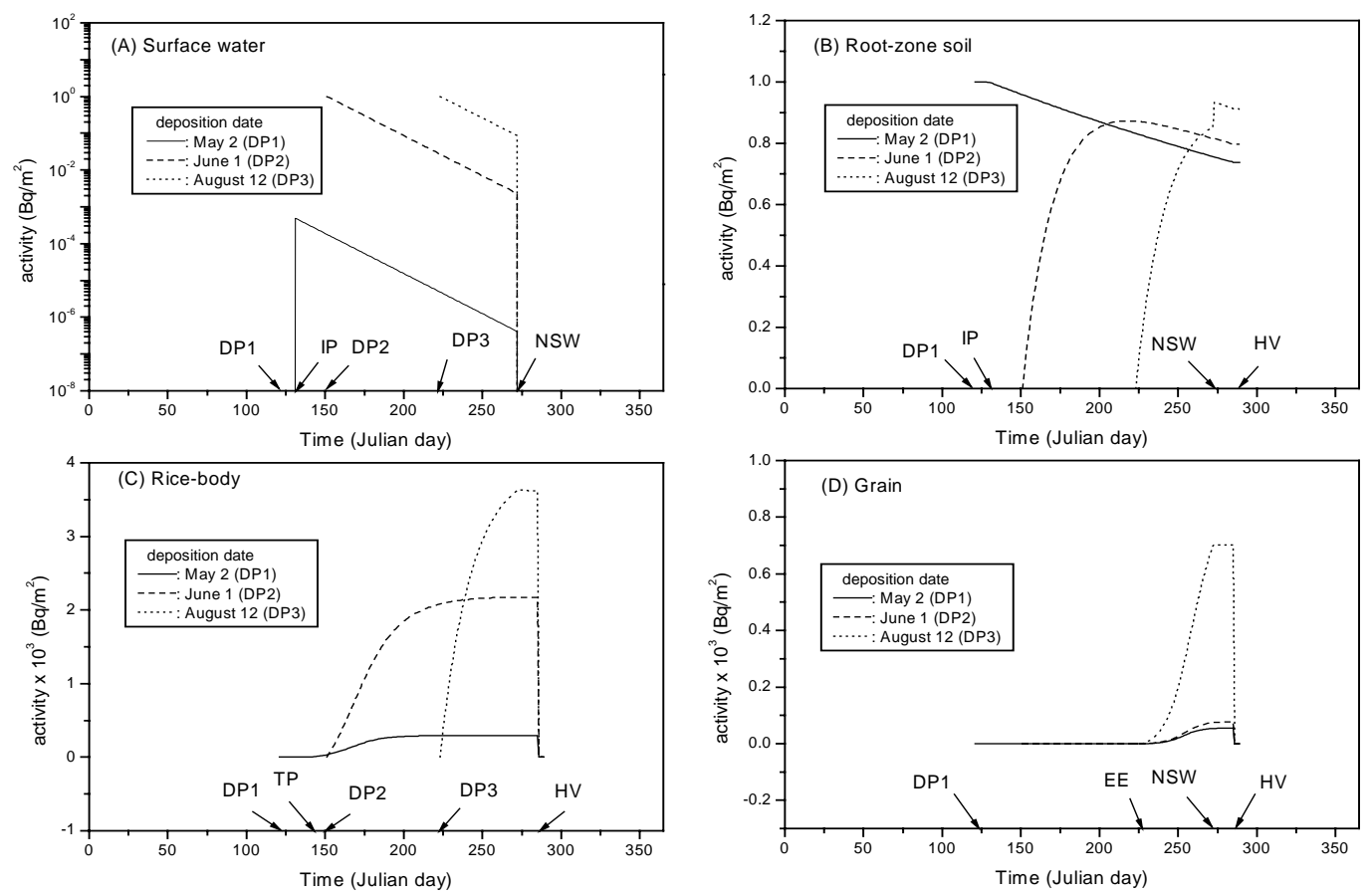

Figure 2. Calculated activity of the four compartments (Kori soil) 
The ploughing leads to a soil mixing and the irrigation causes the desorption of the radionuclide from the soil into the surface water. Percolation and shoot-base absorption gradually decrease the activity of the surface water after an irrigation. However, the influence of both the processes on plant activity is practically negligible since the level of the surface water activity is very low. In the cases of deposition during growth (DP2, June 1 and DP3, August 12), the surface water activity decreases gradually from the beginning of the deposition due to the percolation and shoot-base absorption. The surface water begins to dry up due to the evaporation from the termination of irrigation so that its activity drops drastically at the time of no surface water (NSW, September 30).

The activity of the root-zone soil for the deposition of May 2 (DP1) decreases from the beginning of irrigation and ploughing due to the leaching and fixation processes. For the depositions of June 1 (DP2) and August 12 (DP3), the activity of the root-zone soil increases sharply at the early stages after deposition due to percolation, and afterwards decreases gradually due to the leaching, root-uptake and fixation processes.

The activity of the rice-body and grain increases in the order of the deposition of May 2 (DP1), June 1 (DP2), and August 12 (DP3). This result originates from the difference in the dominant transfer process. Although it is not shown in the figure, in the case of the deposition of May 2 (DP1) the flux of the root-uptake of the body was much higher than that of the shoot-base absorption, indicating that the root-uptake absorption dominates the transfer of the radionuclide to the body. On the contrary, in the cases of the deposition of August 12 (DP2) and June 1 (DP3), the flux of the shoot-base absorption of the body was much higher than that of the root-uptake of the body. The flux of the shoot-base absorption of the body was the highest at the early stages of the deposition of August 12, when the rice-body was fully developed. Conclusively, when deposition occurs during the growing season, the shoot-base absorption contributes to a higher activity of the rice-body.

On the other hand, there is little difference between the activity of the grain for the deposition of May 2 (DP1) and June 1 (DP2). This is due to the fact that the deposition of both cases happened before ear-emergence. If a deposition occurs between the transplanting and the ear-emergence dates, the deposited radionuclide will be transported into the rice-body mainly by means of the shoot-base absorption. With the approach of the deposition date closer to the ear-emergence date (August 16), the transfer of the radionuclide from the surface water to the root-zone soil via percolation will become relatively small so that the surface water activity decreases only a little, and eventually leads to a high flux of the shoot-base absorption to the grain. As a result, the highest activity of the grain is obtained in the case of the deposition of August 12 (DP3).

\subsection{Comparison of the model with the experiments}

Figure 3 shows the comparison of the model prediction with the measured transfer factor
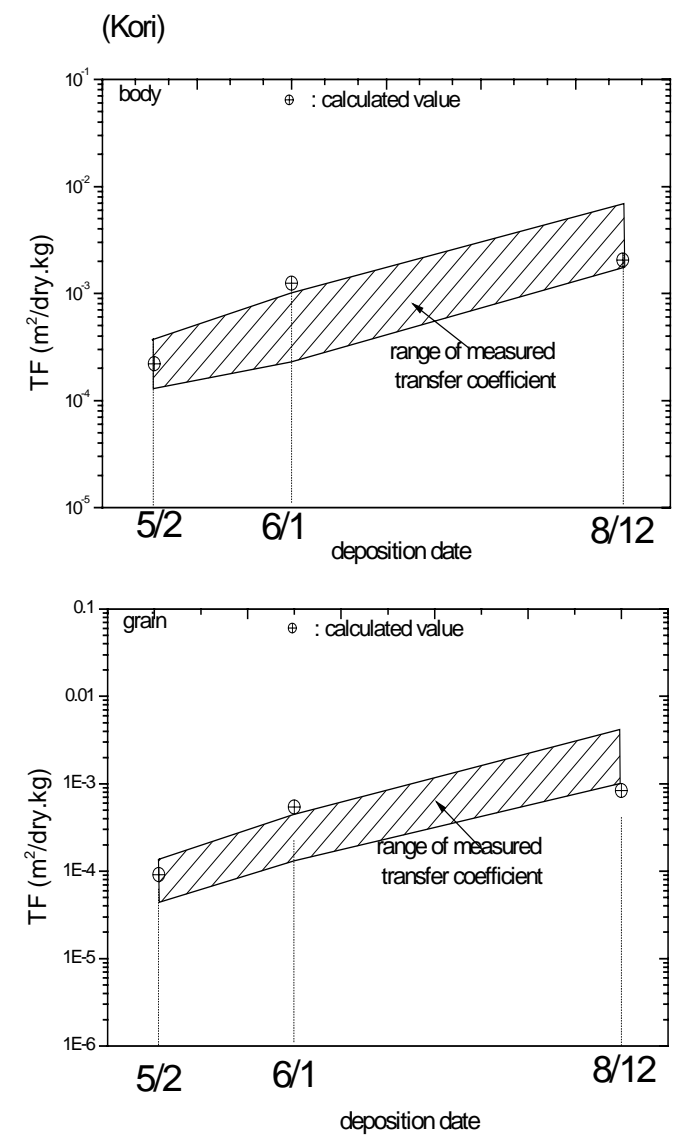

Figure 3. The comparision of the model with the measured data (Kori soil) 
$\left(\mathrm{TF}^{1}\right)$ for the experiment with the Kori soil. The measured transfer factors were in the range of $1.3 \times 10^{-4} \sim 4.0 \times 10^{-4}$ (May 2), $2.3 \times 10^{-4} \sim 1.0 \times 10^{-3}$ (June 1) and $1.8 \times 10^{-3} \sim 6.9 \times 10^{-3}$ (August 12) for the rice-body, and $4.4 \times 10^{-5} \sim 1.4 \times 10^{-4}$ (May 2), $1.3 \times 10^{-4} \sim 4.5 \times 10^{-4}$ (June 1) and $1.0 \times 10^{-3} \sim 4.2 \times 10^{-3}$ (August 12) for the grain, respectively. For the deposition of the same date, the spread of the measured transfer factor is attributed to the soil properties, e.g. the $\mathrm{pH}$ of the soil pore water, cation exchange capacity (CEC), and the content of clay, potassium and calcium in soil, which has an influence on the rate of the root-uptake and leaching to the deep soil. The calculated transfer factors for both the rice-body and grain agree to the mean value of the transfer factor measured for each deposition within one or two factors. Also, the present model simulates well the observed trend of the experiment, of which the transfer factor is increased in the order of the deposition of May 2 (DP1), June 1 (DP2), and August 12 (DP3). This result is possible with a consideration of the shoot-base absorption in the model. In the model without the pathway of a shoot-base absorption, the radionuclide is transported to the plant through the pathway of a root-uptake by way of percolation after a deposition onto the surface water. This will preferably lead to a result opposite to the experiment because an earlier deposition allows for a greater transfer of the radionuclide through the root-zone soil.

Figure 4 shows the comparison of the model prediction with the measured transfer factor for the experiments with the Yonggwang and Ulchin solis. In a similar manner to the present results of the model prediction, the transfer factor decreases normally with time after the deposition of the first year due to the removing processes of radionuclide from the root-zone soil such as the leaching to a deep soil or fixation process (see Figure 1), and consequently a lesser root uptake. The transfer factor obtained in recent year shows a rather higher value than the model prediction, which seems to be caused by the yearly variation of the amount of biomass harvested, but the model agrees well to the experimental result within one order of magnitude.

\section{CONCLUSION}

The transfer of radionuclide to the rice-plant depends on the deposition time (the growing stage of rice-plant), i.e., the transfer factor for the rice-body is dominated by the root-uptake for the deposition before transplanting, and the shoot-base absorption for the deposition during the growth season. The transfer factor for the grain is dominated by the root-uptake for the deposition before or at a short period after transplanting, and the shoot-base absorption for the deposition around the time of ear-emergence.

\footnotetext{
${ }^{1} \mathrm{TF}\left(\mathrm{m}^{2} / \mathrm{kg}\right.$-dry $)=($ activity of each part of plant $) /($ total activity deposited on unit area $)$.
} 
The present model predicts well not only the increasing tendency of the transfer factor due to the shoot-base absorption in the first year of deposition, but also agrees to the transfer factor measured for several years within one order of magnitude. Conclusively, the model can be useful for simulating the transfer of accidentally released radionuclide onto a flooded rice-plant.

\section{Acknowledgements}

This study was financially supported by the Nuclear Research Program of MOST, Korea.

\section{References}

[1] H. Müller, G. Pröhl, Health Physics, 64 (1993) 232-252.

[2] F.W. Whicker, T.B. Kirchner, Health Physics, 52 (1987) 717-737.

[3] M. L. Abbott, A.S. Rood, Health Physics 66 (1994) 17-29.

[4] W.T. Hwang, G. Cho, M.H. Han, J. of Nuclear Science and Technology, 35(6) (1998) 451-461.

[5] T.J. D’Souza, K.B. Mistry, Plant and Soil, 55 (1980) 189-198.

[6] C. Myttenaere, P. Bourdeau, M. Masset, Health Physics, 16 (1969) 701-707.

[7] D.K. Keum, H.S. Lee, H.J. Choi, H.S. Kang, C.W. Lee, J. Environmental Radioactivity, 76(3) (2004) 340-367.

[8] Y.H. Choi, K.M. Lim, H.K. Park, H.J. Choi, H.S. Lee, J. of Korean Association for Radiation Protection, 27(4) (2002) 207-215.

[9] H.S. Lee, C.W. Lee, Y.H. Choi, H.J. Choi, Terrestrial Radioecology and Food Chain Modeling for Nuclear Accident, Korea Atomic Energy Research Institute, KAERI/RR-236/2002 (2002). 